\title{
EDITORIAL
}

\section{Award for Ting C. Huang}

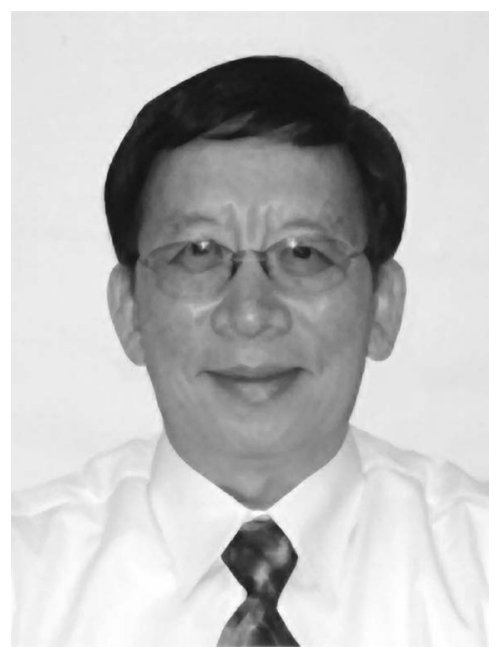

Ting C. Huang, Editor-in-Chief of Powder Diffraction, has received an award recognizing his tremendous contributions to the science and development of the Denver X-ray Conference. The award was presented to Ting by his colleagues and peers on the Denver X-ray Conference Organizing Committee. This award was also fully and enthusiastically endorsed by the Board of Directors of the ICDD, sponsors of DXC and Powder Diffraction.

Ting has been a force of change and development in the field of powder diffraction. After a long and distinguished career, Ting retired as a Research Staff Member Emeritus from the renowned IBM Almaden Research Center in San Jose, California. During his career, he received four invention achievement awards from IBM. Both as an IBM employee, and in subsequent private employment, he focused on global developments in both crystallography and diffraction science. In addition to currently being Editor-in-Chief of Powder Diffraction, he is Associate Editor-in-Chief for the Rigaku Journal and, until recently, Editor-in-Chief of Advances in X-ray Analysis (AXA are the proceedings of the Denver X-ray Conference). These three publications account for 150-200 scientific publications on an annual basis. As Editor-in-Chief he has promoted and promulgated interna- tional participation from global laboratories working in materials development and characterization.

Ting has been particularly instrumental in encouraging the development of crystallographic and diffraction communities in Asia. He has been a visiting professor at both Kwang-si University in China (2001-present) and Tsin-hua University in Taiwan (1997-1998). He was the Chief Technical Advisor to the United Nations Development Program at the Chinese National Microanalysis Center for Electronic Materials and Devices in Shanghai, China (1993-1994). He has been a frequent participant and supporter of the Chinese National Powder Diffraction meeting. Ting coordinated an issue devoted to the technical highlights of this meeting in Powder Diffraction, No. 3 (2004). Ting's many contacts have enhanced international contributions to both the Denver X-ray Conference and AXA proceedings. In 1993, Ting was awarded the German Alexander von Humboldt Award for Senior Distinguished U.S. Scientists (1992-1993).

To his many friends and colleagues who have worked with Ting in his many scientific roles (scientist, organizer, editor) and endeavors, he is admired for both his mind and his enthusiastic personality. Please join us in congratulating Ting on receiving this award.
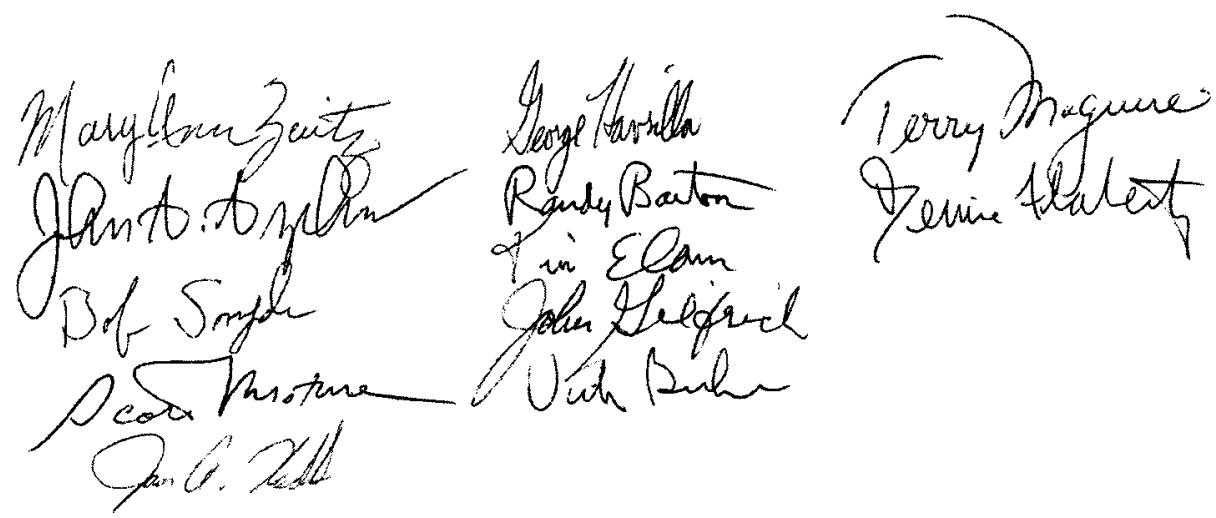

Denver X-ray Organizing Committee 